\title{
Current Treatment Options and New Developments in Metastatic Breast Cancer
}

\section{Metastatik Meme Kanserinde Güncel Tedavi Seçenekleri ve Yenilikler}

\author{
Ülkü Yalçıntaş Arslan ${ }^{1}$, Berna Öksüzoğlu ${ }^{1}$ \\ ${ }^{1}$ SUAM Dr.Abdurrahman Yurtaslan Ankara Onkoloji Eğitim ve Araştırma Hastanesi Tıbbi Onkoloji Kliniği
}

Dergiye Ulaşma Tarihi: 26.02.2019 Dergiye Kabul Tarihi: 25.04.2019 Doi: 10.5505/aot.2019.99266

\section{ÖZET}

Metastatik meme kanserinde sağkalım sonuçları son 20 yılda iyileşme gösterse de halen kadınlarda önemli bir morbidite ve mortalite nedeni olmaya devam etmektedir. Son yıllarda geliştirilen yeni tedavi ajanları ile hormon reseptörü pozitif metastatik meme kanserinde ve/veya HER2-pozitif tümörlü hastalarda anlamlı sağkalım artışları sağlanmıştır. Kombinasyon veya tek ajanlı tedavide, metastatik üçlü negatif meme kanserinin sağkalımı açısından bilinen sitotoksik ajanlarla anlamlı bir iyileşme sağlanamamıştır. Bu derleme güncel tedavi yaklaşımları ve metastatik meme kanseri için yeni tedavi arayışlarına odaklanmıştır.

Anahtar Kelimeler: Metastatik, Meme Kanseri, Tedavi

\begin{abstract}
Although, life expectancy of metastatic breast cancer has improved over the last 20 years, it still remains a significant cause of morbidity and mortality in women. New drugs that were developed in recent years have provided significant survival benefits in the treatment of hormone receptor positive and/or HER2-positive breast cancer. Whether in combination or single-agent therapy, no significant improvement were obtained with the known cytotoxic agents in terms of survival of metastatic triple negative breast cancer. This review has focused on the current treatment approaches and the trials seeking challenging treatment options for metastatic breast cancer.
\end{abstract}

Keywords: Metastatic, Breast Cancer, Treatment

\section{GİRIŞ}

Meme kanseri kadınlarda küresel bir sağlık problemidir. Dünyada 2,1 milyon yeni vaka/yıl/dünya ve 627.000 ölüm/yıl/dünya beklenmektedir(1). Türkiye'de tanı anında \%11,1' i metastatik hastalık ile başvurmaktadır(2).Erken evre meme kanserinde vakaların yaklaşık \%30'da nüks gelişmektedir(3). Metastatik meme kanserinde (MMK) geçmiş yıllara oranla sağkalımın uzadığı bildirilmiştir (4). $\mathrm{Bu}$ iyileşmede tedaviye son yıllarda katılan sitotoksik ve hedef ajanların katkıs1 vardır. $\mathrm{Bu}$ makalede metastatik meme kanserinde kullanılan güncel tedaviler ve yeni tedavi arayışları ile ilgili çalışmalar gözden geçirilecektir.

MMK tedavisinde tedavinin amaçları: Semptom palyasyonu, hayat kalitesini artırmak, sağkalımı uzatmak ve tümör cevabı sağlamak şeklinde özetlenebilir. Tedaviye başlarken öncelikle göz önünde bulundurulması gerekenler arasında daha önce aldığı tedaviler, hastalıksız sağkalım süresi, tümör biyolojisi (ER ve HER2 durumu) ve yandaş hastalık varlığı sayılabilir. Ayrıca varolan sosyoekonomik sorunlar, ilaca erişimdeki problemler, hasta uyumu ve normal fonksiyonlar1 etkileyebilecek olan toksisiteler tedavi kararlarını etkilemektedir.

\section{Endokrin tedaviler (ET):}

Meme dokusundaki ER'yi antagonize eden selektif österojen reseptör modülatörü olan tamoksifen (Tam) 1977'de kullanıma girmiştir (5). Bin dokuzyüz doksanlı yıllarda postmenopozal kadınlarda österojen üretimini inhibe eden aromataz inhibitörleri(Aİ) yeni bir çığır açmıştır $(5,6,7)$. Bunlardan anastrozol(A) ve letrozol(L) nonsteroidal (NSAI) ve eksemestan steroidal yapıda bir Aİ dir (8). Fulvestrant 2000'li yıllarda yapılan çalışmalarla postmenopozal MMK endokrin tedavide 2. ve sonraki basamaklarda yer almıştı (9). İlk sıra tedavideki yeri aşağıda bahsedilecektir. Fulvestrant etkisini ER dimerizasyonunu bozup, ER 
y1kımını artırma ve ER'nin nükleer lokalizasyonunu engelleme yolu ile gösterir(10).Son 10 yılda kombinasyon tedavileri giderek önem kazanmaktadır (örn; eksemestan/everolimus, çeşitli sikline bağımlı kinaz inhibitörleri ile ET kombinasyonları gibi).

Hormon reseptör pozitif MMK de ilk sıra tedaviler

Premenopozal kadınlar: Premenopozal kadınlarda; genel olarak over ablasyonu veya supresyonu sonrasında postmenapozal tedavi yaklaşımları uygulanmaktadir.

Postmenopozal kadınlar: İlk sira tedavide bir aromataz inhibitörünün kullanılması standard yaklaşımlardan birini oluşturur. Anastrozol(A) ve letrozol ile tamoksifen karşılaştırıldığı çalışmalarda progresyona dek geçen süre (TTP) sırası ile 10.7 vs 6.4 ay ve 9.4 vs 6.0 ay olarak Aİ lehinedir, ayrica exemestan da PFS açısından 9.9 vs 5.8 ay ile tamoksifene üstündür $(11,12,13)$. Yirmi beş randomize çalışmanın yeraldığı $(\mathrm{n}=8504)$ bir meta-analizde genel sağkalım açısından ilk sıra endokrin tedavide Aİ kullanmanın tamoksifene üstün olduğu (HR $0.89, \quad \% 95$ CI $\quad 0.80-0.99$ ) bulunmuş̧ur(14).

İlk sıra Aİ yerini alabilecek diğer ajanlar ile ilgili çalışmalar daha yenidir. Faz II FIRST çalışması ile postmenopozal MMK'da ilk sira anastrozol $1 \mathrm{mg}$ $(\mathrm{n}=103)$ ile fulvestrant $500 \mathrm{mg}(\mathrm{n}=102)$ vs anastrozol karşılaştırılmıştır. Birincil sonlanım noktası klinik fayda oranı $(\mathrm{CBR}=$ tüm cevap oran $1+24 \mathrm{hft}$ veya daha uzun stabil hastalık) olan çalışmada sonuçta CBR (\%72.5 vs 65) ve OR benzer (\%36 vs 35.5) idi. TTP, fulvestrant kolunda ulaşılamamışken anastrozol kolunda 12.5 ay (HR, 0.63; \%95 CI, 0.39 ila 1.00; P = .0496) bulundu. İlk sira fulvestrant, anastrozol kadar etkin olduğu sonucuna varıldı(15). Planlanmamış son analizde, Fulvestrant için OS anastrozoldan üstün (54.1 ay ile 48.4 ay HR 0.70 (0.50 to $0.98 ; \mathrm{P}=.04)$ idi( 16$)$.

Faz II çalışmadaki olumlu sonuçlar, faz III FALCON çalışmasına öncülük etti. MMK'inde birinci sıra tedavide anastrozol $(\mathrm{n}=232)$ vs fulvestrant 500 $m g(n=230)$, tamamen endokrin naiv veya endokrin tedavi en az 6 ay önce tamamlanmış hastalarda randomize edildi. Ortanca PFS 16.6 vs 13.8 ay (HR:0.79;\%95 CI0.63-0.99,p=0.0486) bulundu. Daha da etkileyci olan ise altgrup analizinde eğer viseral hastalık yoksa PFS 22.3 aya karşın 13.8 ay ile Fulvestrant lehineydi. ORR ve CBR oranları benzerdi(17). $\mathrm{Bu}$ çalışmanın sonucuna göre fulvestrant postmenopozal MMK'li hastalarda ilk sıra tedavi olarak önerilmektedir.

MMK endokrin tedaviye direnç 2 şekilde ortaya çıkar. Vakaların \%50'si başlangıçta tedaviye dirençlidir, ayrıca başta cevaplı olanlarda zaman içinde endokrin tedaviye direnç geliştirir(18). Başlangıçta veya sonradan direnç gelişme mekanizmaları benzer ama tam olarak açıklığa kavuşturulmuş değildir(19). PI3K yolağında aktivasyon endokrin tedaviye direncin bir işaretidir(19). PI3K mutasyonu olan hastalarda PI3K inhibitörlerinin ET ile birlikteliği çalışılmaktadır. Ayrıca ET direnci kırmak için hücre siklusunu G1 fazında durdurup $\mathrm{S}$ fazına geçişi engelleyen sikline bağımlı kinaz 4/6 inhibitörleri (CDK 4/6 inhibitörleri) ile ET kombinasyonları çalışılmış ve rutin kullanımı önerilmektedir(20).

Tablo-1. HR+/HER2- MMK Hormonoterapi + CDKİ ile yapılan önemli faz III çalışmalar

\begin{tabular}{|c|c|c|c|c|c|}
\hline Çalışma & $\begin{array}{l}\text { Tedav } \\
\text { i sırası }\end{array}$ & Tedavi kolları & ORR & $\begin{array}{c}\text { PFS } \\
\text { ay }\end{array}$ & $\begin{array}{c}\text { HR } \\
\% 95 \mathrm{CI}\end{array}$ \\
\hline $\begin{array}{l}\text { PALOMA-2 } \\
(\mathrm{n}=666)\end{array}$ & 1. sira & Letrozole \pm Palbociclib & $\% 55$ vs $\% 39$ & 24.8 vs 14.5 & $\begin{array}{l}0.58(0.46- \\
0.72)\end{array}$ \\
\hline $\begin{array}{l}\text { MONALEESA } \\
-2 \\
(\mathrm{n}=668)\end{array}$ & 1. sira & Letrozole \pm Ribosiklib & $\begin{array}{c}\% 54.5 \mathrm{vs} \\
\% 38.8\end{array}$ & 25.3 vs 16.0 & $\begin{array}{l}0.57(0.46- \\
0.70)\end{array}$ \\
\hline $\begin{array}{l}\text { MONARCH-3 } \\
(\mathrm{n}=493)\end{array}$ & 1. sira & $\mathrm{NSAI} \pm$ Abemasiklib & $\% 59$ vs $\% 44$ & 28.1 vs 14.7 & $\begin{array}{c}0.54(0.41- \\
0.72)\end{array}$ \\
\hline $\begin{array}{l}\text { MONALEESA } \\
-7 \\
(\mathrm{n}=672)\end{array}$ & 1. sira & $\begin{array}{c}\text { Ribosiklib } \pm \text { Tmx veya } \mathrm{AI}+ \\
\text { OS }\end{array}$ & $\% 51$ vs $\% 36$ & 23.8 vs 13.0 & $\begin{array}{l}0.55(0.44- \\
0.69)\end{array}$ \\
\hline $\begin{array}{l}\text { PALOMA-3 } \\
(\mathrm{n}=521)\end{array}$ & 2. sira & Fulvestrant \pm Palbociclib & $\begin{array}{c}\% 24.6 \text { vs } \\
\% 10.9\end{array}$ & 9.5 vs 4.6 & $\begin{array}{c}0.46(0.36- \\
0.59)\end{array}$ \\
\hline $\begin{array}{l}\text { MONARCH-2 } \\
(\mathrm{n}=669)\end{array}$ & 2. sira & Fulvestrant \pm Abemasiklib & $\begin{array}{c}\% 48.1 \mathrm{vs} \\
\% 21.3\end{array}$ & 16.4 vs 9.3 & $\begin{array}{l}0.55(0.45- \\
0.68)\end{array}$ \\
\hline $\begin{array}{l}\text { MONALEESA } \\
-3 \\
(\mathrm{n}=726)\end{array}$ & 2. sira & Fulvestrant \pm Ribosiklib & $\% 41$ vs $\% 29$ & 20.5 vs 12.8 & $\begin{array}{l}0.59(0.48- \\
0.73)\end{array}$ \\
\hline
\end{tabular}

\section{Anti-österojen ve hedef tedavi kombinasyonları}

Adress for correspondence: Ankara Onkoloji Hastanesi Tibbi Onkoloji 06200 Ankara - Türkiye 
Bir rapamisin analoğu olan everolimus MMK de endokrin direnç ile ilişkili mTOR yolağını inhibe eden bir ajandır(21). Eksemestan ile kombine everolimus kullanımının tedavi cevabı ve sağkalım ile ilişkisi daha önce non steroidal Aİ kullanmış ve progresyon göstermiş MMK de BOLERO-2 ( $\mathrm{N}=724)$ çalışmasında araştırıldı(22).ORR \%9.5 vs 0.4, Ortanca PFS: 7 vs 3 ay (merkezi değerlendirme 10 vs 4 ay, HR:0.43;p<0.001) bulunmuşsa da OS açısından fark yoktu (ortanca 31 vs 26.6 ay,HR 0.89 , $\% 95$ CI 0.73-1.10)(22).

Pan-PI3K inhibitörü olan buparlisib (Faz II/III BELLE-2 çalışması) inoperabl lokal ileri evre ve MMK Aİ tedavisi altında veya sonrasında progresif hastalığ1 olan HR+/HER2- postmenopozal kadınlarda etkinlik ve güvenlik açısından $(\mathrm{N}=1147)$ değerlendirildi(23). Bu çalışmanın birincil sonlanım noktasi, tüm populasyonda ve PI3K aktivasyon statusa göre PFS olarak belirlendi. İkincil sonlanım ise OS, ORR, CBR, güvenlik, PK, QoL idi. PFS, buparlisib + fulvestrant kombine kullanımında tek başına fulvestrant kullanımına göre anlamlı uzamış bulundu (6.9 vs 5 ay HR: $0.78(0.67-0.89) \mathrm{p}<.001)$. Biyobelirteç arayışları ile yapılan eksplaratuar analizlerde, PI3K-aktive hastalarda kombine kolda PFS ortanca 6.8 (4.9-7.1), fulvestrant ile 4.0 (3.15.2) HR: 0.76 (0.60-0.97) $\mathrm{p}=.014$ idi. ctDNA PIK3CA mutant ise PFS ortanca 7 ay kombine kol, 3.2 ay tek fulvestrant için HR: $0.56(0.39-0.80) \mathrm{p}<$ .001. ctDNA PIK3CA mutant olmayanlarda tedaviye bularlisib eklemenin faydası yoktu (6.8 vs 6.8 ay). Greyd 3/4 yan etki deneysel kolda daha fazlaydı: buparlisib $(63.2 \% / 14.1 \%)$ vs plasebo $(27.4 \% / 4.6 \%)$. Buparlisib ile karaciğer toksisitesi de $\operatorname{artmişt1}(23)$.

ASCO 2018 toplantısında sunulan başka bir faz III plasebo kontrollü çift kör randomize çalışmada (SANDPIPER) daha önce Aİ almış MMK'lı hastalarda bir PI3K inhibitörü olan taselisibin, fulvestrant ile kombine tedavide etkinliği araştırıldı. PI3K mutasyonlu 516 hastanın ortanca PFS deneysel kolda 2 ay daha uzundu (7.4 vs 5.4 ay, HR $0.70, p=0.0037)$. ORR açısından da taselisib lehine sonuçlar bulunmuştu (\%29 vs 11.8, p=0.0002). Genel sağkalım verisi henüz olgunlaşmamıştı(24).

Çok yeni olarak ESMO 2018 toplantısında sunulan plasebo kontrollu SOLAR-1 çalışmasında bir PI3K inhibitörü olan alpelisibin fulvestranta eklenmesinin etkinliği değerlendirildi(25). Ortanca 20 aylık izlemde, PI3K-mut+ grupta PFS deneysel kol lehine bulundu (HR 0.65; 95\% CI 0.50-0.85; $\mathrm{P}=0.00065$; ortanca 11.0 vs 5.7 ay)(25).

Faz II ENCORE301 ( $\mathrm{n}=130)$ çalışmasında bir oral, histone deasetilaz inhibitörü olan Entinostatın eksemestan tedavisine eklenmesinin etkinlik ve sağkalım üzerine etkisi araştıııldı(26).Daha önce adjuvan veya metastatik hastalık için NSAİ kullanmış veya kullanmamış bir hasta populasyonunda önceki NSAİ kullanma durumuna (adjuvan veya metastatik NSAI) ve sadece kemik metastazı (var/yok)durumuna göre tabakalandırıldı. Entinostat PFS (4.3 vs 2.3 ay, HR 0.73 ; 95\% CI, 0.50 to 1.07 ; one-sided $\mathrm{P}=.055$; two-sided $\mathrm{P}=.11$ ) ve OS (28.1 vs 19.8 ay, HR $0.59 ; 95 \%$ CI, 0.36 to $0.97 ; \quad \mathrm{P}=.036)$ anlamlı olarak artırdı $\mathrm{g} 1$ görüldü.Greyd 3/4 AEs olarak, nötropeni $(15 \%$ entinostat vs $0 \%$ plasebo) ve halsizlik (13\% entinostat vs $3 \%$ plasebo) ön plandaydı. Protein hiperasetilasyonu olan hastalarda etinostat tedavisi PFS uzatt1(26).

Faz III E2112 çalışmasında NSAİ alırken veya sonrasinda progrese olmuş,HR+/HER2-, inoperabl, lokal ileri veya MMK'li Pre/peri/postmenopozal kadın ve erkek hastalarda Eksemestan tedavisine Entinostat eklemenin etkinliğinin araştırılması planlanmıştır $(\mathrm{N} \sim 600)(27)$.

\section{Anti-östrojen ve CDKI tedavi:}

Faz II PALOMA-1 çalışmasında bir CDK 4/6 inhibitörü olan palbosiklib ile letrozol vs letrozol karşılaştırıldı( 28). Bu Faz II açık etiketli randomize çalışması ile Şubat 2015 de FDA onayı aldı. PALOMA-1/TRIO-18 çalışmasına(n=165) Postmenopozal MMK kadın hastalar alınmıştı. Letrozol + palbosiklib(125 mg/gün PO $3 \mathrm{hft}, 1 \mathrm{hft}$ ara ile/28günde bir) vs letrozol progresyona veya kabul edilemez toksisiteye kadar verildi. Ortanca PFS, Palbosiklib + letrozole $(\mathrm{n}=84)$ kolunda 20.2 ay iken Letrozole $(\mathrm{n}=81)$ kolunda 10.2 ay bulundu. Faz III PALOMA-2 çalı̧̧masında palbosiklib ile letrozolun tek başına letrozole olan PFS üstünlüğ̈ gösterildi (Ortanca PFS 24.8 ay vs 14.5 ay, HR 0.58 ;\%95 CI,0.46-0.72; $\mathrm{p}<0.001)$ (29).

Faz III PALOMA-3 çalışmasında $(\mathrm{n}=521)$ endokrin tedavi altında progresyon saptanan hastalarda palbosiklib(125 mg/gün PO 21/28 günde bir) + fulvestrant $(500 \mathrm{mg} 1$. ve 15 . günlerde yükleme dozu sonra 28 günde bir İ.M.) kombinasyonunun tek başına fulvestrant üstünlüğü araştırıldı(30).Birincil sonlanım olan PFS açısından deneysel kol standard tedaviye üstündü ( 9.2 vs 3.8 ay,p $<0.001$ ). Daha uzun süreli izleminin sonuçlarında ortanca PFS 9.5 vs 4.6 ay ile halen deneysel kol lehine idi(HR $0.46 \% 95$ CI $0.36-0.59, \mathrm{p}<0.0001$ ). Hastaların \%33'de PIK3CA değerlendirilmişti. PIK3CA veya hormon reseptör durumunun cevap oranlarını etkilemediği gösterildi. En s1k görülen greyd 3/4 yan etki nötropeni idi (\%65 vs \%1)(31).Çok yeni olarak bu çalışmanın genel sağkalım verisi ESMO 2018'de sunuldu(32). Viseral hastalığı olmayan grupta kombinasyon tedavisi 11.5 ay sağkalım avantajı sağlamaktaydı(ortanca 46.9 vs 35.4 ay;HR 0.69[0.46-1.04]). Ayrica önceki endokrin tedaviye duyarl grupta da OS avantaj1 sözkonusu idi (ortanca 39.7 vs 29.7 ay, HR 0.72[0.55-0.94]).

Faz III MONARCH 2 (n=669) çalışmasında 12 aydan kısa sürede neoadjuvan veya adjuvan ET direnç gelişen veya MMK için ilk sıra ET ile progrese olan hastalarda abemasiklib ile fulvestrant 
kombinasyonunun tek başına fulvestrant tedavisine üstünlüğü değerlendirildi(31). Ortanca PFS abemasiklib eklenmesi ile anlamlı olarak uzamıştı (16.4 vs 9.3 ay; HR 0.55,\%95 CI, 0.44-0.68; p0.001) (32). Keza ORR \%48 vs \%21 ile deneysel kolda daha üstündü. Abemasiklib için en dikkat çekici toksisite diyare (\%86 vs 24$)$, nötropeni( $\% 46$ vs $\% 4)$, bulantı (\%45 vs\%23) ve halsizlik idi(\%40 vs\%27)(33).

MONARCH 3 ( $n=493$ )çift kör randomize bir faz III çalışma ile ilk sıra abemasiklib ile bir non steroid Aİ birlikte kullanımının etkinliği değerlendirildi(34). Ortanca PFS plasebo kolunda 14.7 ay iken abemasiklib alan kolda henüz ulaşılamamıştı $(\mathrm{p}=0.000021)$. Ölçülebilen hastalığı olanlarda ORR $\% 44$ vs 59 ( $\mathrm{p}=0.004)$ ile deneysel kolda daha iyiydi. Yine diyare (\%9.5 vs \%1.2) ) ve nötropeni (\%21 vs\%1.2 ) ilk plandaki greyd 3/4 yan etkilerdi.

Diğer bir CDK4/6 inhibitörü Ribosiklib'in faz III plasebo kontrollü randomize çalışmasında (MONALEESA-2) 668 postmenopozal HR+/HER2MMK kadın hastada ilk sira letrozol tedavisine katkısı araştırıldı(35). ORR açısından ribosiklib/letrozol kolu letrozol/plasebo koluna üstündü(\%52.7 vs \%37.1, p<0.001). Ortanca 18 aylık izlemde çalışmanın birincil sonlanımı olan PFS açısından yapılan değerlendirme sonucunda ribosiklib/letrozol kolunda henüz ortanca PFS ulaşılamamışken, diğer kolda 14.7 olarak bulundu(HR,0.56; \%95 CI 0.43-0.72).Bu çalışmanın güncellenmiş sonuçları yeni olarak açıklandığında ortanca PFS 25.3 vs 16 ay ile ribosiklib içeren kol lehine idi(36). Ribosiklib tedavisinin faydası PIK3CA veya TP53 mutasyon durumu, total $\mathrm{Rb}, \mathrm{Ki}$ 67 veya p16 protein ekspresyonu, ve CDKN2A,CCND1 veya ESR1 mRNA düzeyi ile ilişkisiz olarak devam etmekteydi.Tümörde tirozin kinaz wild-tip ise ribosiklib etkinliği daha belirgindi. En s1k görülen greyd 3/4 ribosiklib yan etkisi nötropeni ve lökopeni idi.

Ribosiklib ile yapılan diğer bir faz III çalışmada (MONALEESA-3) daha önce Aİ kullanmış veya hiç tedavi almamış postmenopozal HR+/HER2- MMK kadın hastalarda fulvestrant tedavisine ribosiklibin katkısı araştırılmıştır(37). Bu çalışma 1. basamakta CDK4/6 inhibitörlerinin fulvestrantla kombine edildiği tek çalışma olduğundan önemlidir. OrtancaOrtanca PFS 20.5 vs 12.8 ay ile tedaviye ribosiklib eklenen kolda daha uzundu (HR,0.593;\%95 CI, 0.480-0.732; $\mathrm{p}=0.001$ ). Beklendiği üzere greyd $3 / 4$ nötropeni ribosiklib kolunda daha sıktı (37).

Faz III MONALEESA-7 çalışmasında premenopozal HR+/HER2- MMK kadın hastalarda tamoksifen veya NSAI tedavisine ribosiklib eklenmesinin sağkalım katkısı ve etkinliği araştırıldı(37 ). Hastaların \%45'i daha önce başka bir tedavi almamıştı(n=672, 1:1 randomize). Tüm hastalarda 28 günde bir goserelin $3.6 \mathrm{mg} \mathrm{sc}$ uygulanmıştı. Araştırmacı değerlendirmesine göre ortanca PFS 23.8 vs 13.0 ay ile ribosiklib içeren kol lehine idi (HR,0.55;\%95 CI 0.44$0.69 ; \mathrm{p}<0.0001)$.ORR \% 41 vs \%30 ile ribosiklib içeren kolda daha fazlaydı (38).

Aşağıdaki tabloda HR+/HER2- MMK

Hormonoterapi + CDKİ ile yapılan önemli faz III çalışmaların bir özeti gösterilmektedir. Bu çalışmalardan PALOMA-3 hariç diğerlerinin genel sağkalım sonuçları henüz açıklanmamıştır. $\mathrm{Bu}$ çalışmalar 1şığında birinci dereceden kanıtlar CDK 4/6 inhibitörlerinin endokrin tedavi ile birlikte kullanımını desteklemektedir(20)

HR+ HER2- MMK ilk sira tedavide kemoterapi vs endokrin tedavi mi uygulanmalı sorusuna cevap arayan bir meta-analize alınan 6 çalışmada $(n=692)$ anlamlı OS farkı yoktu (HR: $0.9495 \%$ CI: 0.79$1.12 ; \mathrm{p}=0.5)$. Sekiz çalışmada $(\mathrm{n}=817)$ kemoterapi ile ORR anlamlı artış [HR: 1.25 (95\% CI: 1.01-1.54; $P=.04)$ ] vardı ancak en büyük 2 çalışmada tam tersi eğilim görüldü. $\mathrm{Bu}$ çalışmaların yan etki ve yaşam kalitesi bilgisi yetersizdi. Kemoterapiye bağl1 toksisite artmıştı (bulantı,kusma,alopesi) .Yedi çalışmanın 3'ün de yaşam kalitesi sonuçları var ama farklilık arzediyordu(39).

Hormon reseptör pozitif MMK de kemoterapi kullanımı için öneriler:

Sadece adjuvan tedavi sonrası k1sa hastalıksız sağkalım olması ve/veya asemptomatik viseral metastaz varlığı nedeni ile kemoterapi ile başlamak önerilmez. Kemoterapi önerilecek durumlar şöyle özetlenebilir(40);

- Viseral kriz: ciddi organ disfonksiyonu (semptom, laboratuvar değerlendirme, hizlı klinik bozulma:lenfanjitik akciğer tutulumu, kemik iliği tutulumu, veya ciddi karaciğer metastazı)

- Çoklu basamaklı endokrin tedavi sonrası progresyon HER2 pozitif MMK

HER2, membrana bağlı ERBB tirozin kinaz ailesinin bir üyesidir ve meme kanserlerinin yaklaşık \%20'sinde HER2 gen amplifikasyonuna bağlı olarak aşırı ekspresyonu sözkonusudur $(41,42)$. Ayrıca agresif tümör davranışı ile ilgili olduğu gösterilmiştir(41,42). HER2'ye doğrudan bağlanan bir ligand gösterilmiş değildir. HER2 yolağı, ligand bağlanması ile aktive olmuş EGFR ve ERBB3 ile heterodimer oluşturarak veya kanserlerde olduğu gibi yüksek konsantrasyonlarda olduğunda homodimerizasyon yolu ile aktif hale geçer(42,43). Bunların içinde HER2/ERBB3 heterodimerleri, ERBB3'ün PI3K'nın p85 alt ünitesine bağlanması ile PI3K/AKT yolağını aktifleştiren en potent aktivatörlerdir(44). Amerikan Gida ve İlaç Yönetimi(U.S. Food and Drug Administration) tarafından 1998 de meme kanserinde kullanımı onaylanan trastuzumab $(\mathrm{T})$, bir rekombinant humanize monoklonal antikorudur ve HER2'nin ekstrasellüler kısmının jukstamembran domainini hedef alır(45). Pertuzumab(P), HER2'nin diğer ERBB ailesi üyeleri ile heterodimer -özellikle en 
potent heterodimer olan HER2/CERBB3'ünoluşumunu engelleyen bir monoklonal antikordur(47). T-DM1, T ile mikrotübül inhibe eden emtansin isimli bir sitotoksik ajan kongugatıdır(48). Lapatinib(L), EGFR ve HER2'nin intrasellüler ATP bölgesine yarışmalı olarak bağlanan reversibl bir TKİ'dir(49). HER2+ MMK tedavisinde kullanılan bu ajanlar ve kombinasyonları ile ilgili çalışmalar aşağıda gözden geçirilmişstir.

\section{HER2+ MMK Pratiğimizi Belirleyen Temel}

Çalışmalar: Slamon ve ark. tarafindan yapılan ve 2001 yılında NEJM'de yayınlanan Faz III çalışma ile trastuzumab (T) ve kemoterapi (AC veya paklitaksel) kombinasyonunun ortanca PFS, OS ve ORR artırdığı gösterildi (sırası ile: 7.4 vs 4.6 ay ,p<0.001;25.1 vs 20.3 ay, p=0.046; \%50 vs \%32, $\mathrm{p}<0.001)(50) . \quad \mathrm{Bu}$ çalışmada $\mathrm{AC}+\mathrm{T}$ kombinasyonunun tek başına AC uygulamasına göre kabul edilemez düzeyde kardiyotoksisiteye neden olması nedeni ile (\%27 vs ) paklitaksel ile T kullanımı uygulamada kabul gördü(51). Faz II randomize bir çalışma ile $\mathrm{T}+\operatorname{dosetaksel(D)}$ kombinasyonunun tek ajan dosetaksele üstünlüğü gösterildi(52). Geyer ve ark. tarafından yapılan bir faz III çalışmada, ikinci ve sonraki basamaklarda lapatinib ve kapesitabin kominasyonu gibi başka bir antiHER2 tedavi ajanı içeren tedavi ile devam etmenin faydası gösterildi(53).

Dual HER2 blokajının etkinliğini göstererek pratikteki yaklaşımımızı değiştiren bir faz III çalışma 2012 yılında yayınlandı(54). CLEOPATRA çalışmasında HER2+ lokal ileri veya MMK kadınlarda $(\mathrm{N}=808)$ ilk sira tedavi olarak Trastuzumab ve dosetaksel kombinasyonuna Pertuzumab eklenmeninin etkinliği araştırıldı.Hastalar coğrafi bölge ve önceki(neo)adjuvan kemoterapi alma durumuna göre tabakalanmıştı. Deneysel kola Trastuzumab 6 $\mathrm{mg} / \mathrm{kg} 3 \mathrm{hft}$ bir ile birlikte dosetaksel 75-100 $\mathrm{mg} / \mathrm{m}^{2 / 3} \mathrm{hft}$ bir ve Pertuzumab $420 \mathrm{mg} / 3 \mathrm{hft}$ bir (n = 402) uyguland1. Standart kolda Trastuzumab 6 $\mathrm{mg} / \mathrm{kg} 3 \mathrm{hft}$ bir ile dosetaksel $75-100 \mathrm{mg} / \mathrm{m}^{2} 3 \mathrm{hft}$ bir ve plasebo $3 \mathrm{hft}$ bir $(\mathrm{n}=406)$ Hastalık progresyonu veya kabul edilemez toksisiteye kadar verildi (yükleme dozu T için ilk uygulamada 8$\mathrm{mg} / \mathrm{kg}$ ve $\mathrm{P}$ için 840-mg idi). Minimum 6 dosetaksel kürü verildi ancak kabul edilemez toksisite varsa veya PD durumunda 6 kürden az dosetaksel uygulaması da kabul edildi. Birincil sonlanım noktası bağımsız değerlendirme ile saptanan PFS, ikincil sonlanım araştırmacı değerlendirmesi PFS, ORR, OS, güvenlik idi. Final analiz sonuçlarında P içeren kolda PFS bağımsız değerlendirme sonucunda ortanca: 18.5 ay, kontrol kolunda ortanca: 12.4 ay bulundu (HR: 0.62 (95\% CI: 0.51-0.75); P < $.001)$. Genel sağkalım ise 56.5 vs 40.8 ay olarak pertuzumab içeren kol lehine daha uzundu(55). CLEOPATRA güvenlik verilerine bakıldığında AEs (greyd $\geq 3$ ) olarak febril nötropeni oranı $\mathrm{P}+\mathrm{T}$ kolunda plasebo koluna göre yüksekti(\%13.8 vs 7.6), yine periferal nöropati \%2.7 vs 1.8 ile $\mathrm{P}+\mathrm{T}$ kolu aleyhine idi.Merakla beklenen sol ventrikül sistolik disfonksiyonunda ise bir artış yoktu (\%1.2 vs 2.8)(53).

HER2+ MMK'de Faz III EMILIA (N = 991) çalışmasında daha önce taksan ve $\mathrm{T}$ tedavisi almış HER2+ lokal ileri veya MMK'li hastalarda T-DM1 ile Lapatinib ile kombine kapesitabinin(LX) etkinliği karşılaştırıldı(56). T-DM1 3.6 mg/kg IV 3 hft bir $(\mathrm{n}=496)$ ve kapesitabin $1000 \mathrm{mg} / \mathrm{m}^{2}$ PO günde iki kez, 1-14 gün, 3 hft bir ve Lapatinib 1250 mg/gün PO ( $\mathrm{n}=495)$ PD veya kabul edilemez toksisiteye kadar uyguland. Birincil sonlanım noktası PFS IRF, OS, güvenlik olarak belirlendi.İkincil sonlanım: QoL (FACT B), DoR, araştırmacıya göre PFS, ORR, semptom progresyon zamanı idi. Bağımsız değerlendirme sonucuna göre ortanca PFS 9.6 vs 6.4 ay, ortanca OS ise 30.9 vs 25.1 ay olarak T-DM1 lehine bulundu(56).

TH3RESA çalışmasına daha önce $\geq 2$ anti-HER2 tedavi almış olan 602 HER2+ MMK dahil edildi(57). T-DM1 3.6 mg/kg IV 3 hft bir $(\mathrm{n}=404)$ ve doktor seçimi ilaç $(\mathrm{n}=198)$ progresif hastalık gelişene veya kabul edilemez bir toksisiteye kadar uyguland1. PD halinde T-DM1 çapraz geçişe izin verildi.Doktor seçimi ilaç olarak trastuzumab,lapatinib veya bir taksan verilmişti. Birincil sonlanım noktası araştırmacının bulduğu PFS, OS, ikincil sonlanım ise araştırmacının bulduğu ORR, dor, 6-ay ve 1-yıl sağkalım, güvenlik olarak kabul edildi.

TH3RESA çalışmasının son genel sağkalım analizinde Doktor seçimi ilaç kullanan koldan TDM1'a önemli oranda çapraz geçiş olmasına rağmen (\%44.9) baştan itibaren T-DM1 uygulanan kolda ortanca OS anlamlı iyileşmiş olduğu görüldü(15.6 vs $22.7, \mathrm{p}=0.0002)(55)$. T-DM1 kolunda ilaç kesilmesi daha azdı ( \%67.1 vs \%79.3). Keza TH3RESA çalışmasında T-DM1 ile greyd $\geq 3$ yan etkinin doktor seçimi tedaviden daha az olduğu gözlendi(58).

Blackwell ve ark. tarafından 2010 yılında yayınlanan bir çalışmada $\mathrm{T}$ almış hastalarda ikili antiHER2 tedavinin sadece $\mathrm{T}$ ile HER2 blokajına devam etmeye üstünlüğünü araştırıldı. T ile kombine L alan grupta ortanca PFS açısından istatistiki anlamlı olsa da sınırlı bir fayda sağlanmıştı (8 vs 11 hafta $\mathrm{p}=0.008)(59)$. Son sonuçları 2012 y1lında yayınlandığında PFS ve OS avantajı devam ediyordu (sırasiyla; [HR], 0.74; 95\% CI, 0.58 to $0.94 ; \mathrm{P}=.011$ ve $\mathrm{HR}, 0.74 ; 95 \% \mathrm{CI}, 0.57$ to $0.97 ; \mathrm{P}$ $=.026)(60)$.

Sonuç olarak; Bugün eldeki veriler ile HER2+ MMK de ilk sıra standart tedavi CLEOPATRA çalışmasına istinaden bir taksan ile $\mathrm{T}+\mathrm{P}$ uygulanmasıdır. İkinci sıra tedavide EMILIA çalışması ile T-DM1 yerini almıştır. Üçüncü ve sonraki tedavi sıralamasında henüz en iyi sıralamanın ne olacağı tam olarak 
tanımlanmamıştır. Kapesitabin ve lapatinib kombinasyonu veya eğer 2. sırada kullanılmadı ise T-DM1 TH3RESA çalışmasındaki sağkalım avantajı nedeni ile seçilebilir. Yine bu ajanları kullanmış ve halen progresif hastalık mevcut ise trastuzumab tedavisine bir sitotoksik ajan eklenmesi veya lapatinib ile trastuzumab kullanımı önerilebilir

Tablo-2. Metastatik HER2+ Meme Kanserinde Pratiği Değiştiren Başlıca Çalışmalar

\begin{tabular}{|c|c|c|c|c|c|c|}
\hline Çalışma & $\begin{array}{l}\text { Önceki } \\
\text { sitotoksi } \\
\mathrm{k} \text { veya } \\
\text { hedef } \\
\text { tedavi }\end{array}$ & $\begin{array}{l}\text { Tedav } \\
\text { i sıras1 }\end{array}$ & Tedavi kolları & $\begin{array}{l}\text { ORR } \\
\%\end{array}$ & PFS & OS \\
\hline $\begin{array}{l}\text { Slamon ve } \\
\text { ark. } \\
\text { Faz III n=469 }\end{array}$ & $\begin{array}{l} \pm \\
\text { antrasikli } \\
\mathrm{n}\end{array}$ & 1. & $\begin{array}{l}\text { AC veya } \\
\text { paklitaksel vs } \\
\text { AC veya } \\
\text { paklitaksel + T }\end{array}$ & 50 vs 32 & $\begin{array}{l}7.4 \text { vs } 4.6 \\
p<0.001\end{array}$ & $\begin{array}{l}20.3 \text { vs } 25.1 \\
p=0.046\end{array}$ \\
\hline $\begin{array}{l}\text { Marty ve ark. } \\
\text { Faz II n=186 }\end{array}$ & $\begin{array}{l}\text { antrasikli } \\
\mathrm{n}\end{array}$ & 1. & $\mathrm{D}$ vs $\mathrm{D}+\mathrm{T}$ & 34 vs 61 & $\begin{array}{l}* 6.1 \quad \text { vs } \\
11.7 \\
p=0.0001\end{array}$ & $\begin{array}{l}22.7 \text { vs } 31.2 \\
p=0.0325\end{array}$ \\
\hline $\begin{array}{l}\text { CLEOPATR } \\
\text { A } \\
\text { Faz III n=808 }\end{array}$ & $\begin{array}{l}\text { Antrasikl } \\
\text { in } \\
\text { Taksan } \\
\mathrm{T}^{* *}\end{array}$ & $\boldsymbol{\beta}_{1}$. & $\mathrm{D}+\mathrm{T}$ vs $\mathrm{D}+\mathrm{T}+\mathrm{P}$ & $\begin{array}{ll}69.3 & \text { vs } \\
80.2 & \end{array}$ & $\begin{array}{l}12.4 \quad \text { vs } \\
18.7 \text { ay } \\
\mathrm{p}<0.001\end{array}$ & $\begin{array}{l}40.8 \text { vs } 56.5 \\
\text { ay } \\
p<0.001\end{array}$ \\
\hline $\begin{array}{l}\text { EMİLİA } \\
\text { Faz III n=991 }\end{array}$ & $\begin{array}{l}\mathrm{T} \text { ve } \\
\text { taksan }\end{array}$ & 2. & $\begin{array}{l}\text { Kapesitabin +L } \\
\text { vs } \\
\text { T-DM1 }\end{array}$ & $\begin{array}{ll}30.8 & \text { vs } \\
43.6 & \end{array}$ & $\begin{array}{l}6.4 \text { vs } 9.6 \\
\text { ay } \\
p<0.001\end{array}$ & $\begin{array}{l}25.9 \text { vs } 29.9 \\
\text { ay } \\
p<0.001\end{array}$ \\
\hline $\begin{array}{l}\text { TH3RESA } \\
\text { Faz III n=602 }\end{array}$ & $\begin{array}{l}\mathrm{T}, \text { taksan } \\
\text { ve } \mathrm{L}\end{array}$ & $\geq 2$ & $\begin{array}{l}\text { Dr'un seçimi } \\
\text { tedavi } \\
\text { vs } \\
\text { T-DM1 }\end{array}$ & 9 vs 31 & $\begin{array}{l}3.3 \text { vs } 6.2 \\
\text { ay } \\
p<0.0001\end{array}$ & $\begin{array}{l}15.8 \text { vs } 22.7 \\
\text { ay } \\
\text { p }<0.0001\end{array}$ \\
\hline $\begin{array}{l}\text { Geyer ve } \text { ark. } \\
\text { Faz } \\
n=399\end{array}$ & $\begin{array}{l}\text { T, taksan } \\
\text { ve } \\
\text { antrasikli } \\
\text { n }\end{array}$ & $\geq 2$ & $\begin{array}{l}\text { Kapesitabin } \\
\text { vs } \\
\text { Kapesitabin + L }\end{array}$ & 14 vs 22 & $\begin{array}{l}4.3 \text { vs } 6.2 \\
\text { ay } \\
p=0.002\end{array}$ & $\begin{array}{l}15.3 \text { vs } 15.6 \\
\text { ay } \\
p=0.72\end{array}$ \\
\hline $\begin{array}{l}\text { Blackwell ve } \\
\text { ark. } n=296\end{array}$ & $\mathrm{~T}$ & $\geq 2$ & $\mathrm{~L}$ vs $\mathrm{L}+\mathrm{T}$ & $\begin{array}{ll}6.9 & \text { VS } \\
10.3 & \end{array}$ & $\begin{array}{l}8^{\alpha} \text { hft vs } 11 \\
\text { hft } \\
p=0.011\end{array}$ & $\begin{array}{l}10 \text { vs } 14 \text { ay } \\
p=0.026\end{array}$ \\
\hline
\end{tabular}

*TTP:progresyona kadar geçen süre;**adjuvan $\mathrm{T}$ alan \%10 hasta, ${ }^{\boldsymbol{\beta}}$ bir y1ldan sonra nüks etmiş hastalar, ${ }^{\boldsymbol{a}}$ hft:hafta, D:Dosetaksel,T:trastuzumab,P:pertuzumab,L:Lapatinib

Ayrıca her2-pozitif MMK'de yapılan faz II çalışmalarda paklitaksel ve vinorelbinin ikili HER2 blokajı ile kombine kullanımı (pertuzumab ve trastuzumab) etkinlik ve güvenlik açısından araştırılmıştır (61,62). Paklitaksel ve $\mathrm{P}+\mathrm{T}$ kombinasyonu ile ilk basamak tedavi alanlarda ortanca PFS 24.2 ay olarak bulunmuștur(61). HER2pozitif MMK'de ilk sıra tedavide dosetaksel ve $\mathrm{P}+\mathrm{T}$ kombinasyonunun kullanılamadığı hastalarda paklitaksel bir alternatif olarak güncel NNCN rehberi tarafindan önerilmektedir(40). VELVET çalışmasının ilk kohortuna dahil edilen 106 hastada ilk sira vinorelbin ve $\mathrm{P}+\mathrm{T}$ kombinasyonu ile ORR \%74.2 ve ortanca PFS 14.3 ay bulunmuştur (63). Taksan kullanılamadığı durumlarda bir alternatif olarak P+T tedavisine eklenebilir.
(40).Ülkemizde 2. basamaktan sonra trastuzumabın diğer ajanlarla veya tek başına kullanımı sağlık otoritesinin iznine tabidir. Tablo-2 de HER2+ MMK'de yapılmış ve pratiği belirleyen çalıșmaların bir özeti yer almaktadır.
Faz III MARİANNE çalışmasında ilk basamak tedavide trastuzumab ve bir taksan kombinasyonu ile sadece T-DM1 ve T-DM1 ve pertuzumab kombinasyonu karşılaştırıldı Ortanca PFS sırası ile 13.7 vs 14.1 vs 15.2 ay olarak bulundu(64). Ancak sağkalım açısından (ortanca sağkalım sırası ile 50.9 vs 53.7 vs 51.8 ay) metastatik ilk sira T-DM1 bir üstünlük sağlamamaktaydı(64). Bu veriler 1şığında T-DM1 HER2-pozitif MMK ilk sira tedavisinde rutin kullanım açısından önerilmemektedir.Ancak trastuzumab-taksan kombinasyonuna non inferior bulunmuş olması nedeni ile bu kombinasyonun kullanılamadığı durumlarda bir seçenek olabilir(40) 


\section{Üçlï Negatif Meme Kanseri}

Üçlü negatif meme kanseri(ÜNMK), tüm meme kanserlerinin yaklaşık \%10-15 oluşturur ve erken nüks, kısa sağkalım ile ilişkilidir(65). Her nekadar farklı araştırmacılar tarafından değişen sayıda ÜNMK alt tipi tanımlanmışsa da Le $\mathrm{Du}$ ve arkadaşları tarafindan yapılan çalışmada kişiselleştirilmiş tedavi verebilmek açısından, bazal hücre benzeri, mezenşimal hücre benzeri, immün tip, luminal/apokrin androjen(AR) reseptörü aşırı eksprese eden tip ve HER2-zengin tip olarak 5 moleküler alt tipi belirlenmiștir(66,67,68,69). Bu tiplerin özelliklerine göre geliştirilebilecek tedaviler halen önemli bir araştırma konusudur.

Metastatik HR+/HER- veya HER2+ hastalıkta sağlanan sağkalım iyileşmesinden bu hasta grubunda henüz bahsedilemez. Amerikan NCCN rehberinin MMK de önerdiği kemoterapi rejimleri üçlü negatif MMK için de kullanılmaktadır. Eğer hızla ilerleyen hastalık,viseral kriz,yüksek tümör yükü yoksa tek ajan tercih edilebilir: antrasiklinler (doksorubisin, pegile lipozomal doksorubisin),taksanlar(dosetaksel, paklitaksel), antimetabolitler (kapesitabin, gemsitabin) ve mikrotübül inhibitorleri (eribulin, ixabepilon, vinorelbin) gibi. Kemoterapi Kombinasyonları olarak ilk sira tedavide sik kullanılan AC (doksorubisin/ siklofosfamid) ve EC (epirubisin, siklofosfamid), FAC (5FU, doksorubisin, siklofosfamid), FEC (5FU, epirubisin, siklofosfamid) gibi antrasiklin içeren kombinasyon tedavilerinin yanısıra GT (gemsitabin, paklitaksel), dosetaksel/ kapesitabin, gemsitabin/karboplatin veya $\mathrm{CMF}$ (siklofosfamid,mtx,5FU) daha önce kullanılmış olan ajanların durumuna göre tedavi seçeneklerinde yer almaktadır(40). Çoğu üçlü negatif meme kanserli hasta adjuvan olarak antrasiklin, taksan ve siklofosfamid ile tedavi edilmiş olmakta ve metastatik dönemde standard kemoterapiler ile PFS $\leq 4$ ay olmaktadır (70).

MMK hastalarda ilk sira tedavide gemsitabin ve paklitaksel ile tek başına paklitaksel karşılaştırılmış ve OS,TTP ve ORR açısından kombine kol üstün olarak bulunmuştur (71) Ayrıca kapesitabin ve dosetaksel kullanımı tek ajan taksan tedavisine OS,TTP ve ORR açısından üstündü (72). Bu çalışmada tek ajan dosetaksel alan koldaki hastalar çalışma sonrasında kapesitabin aldığında diğer sitotoksik ajanları alanlara göre sağkalım daha iyiydi (73).Diğer bir çalışmada kombinasyon kemoterapinin sağkalım üstünlüğ̈̈ gösterilememiş ve toksisitenin daha fazla olduğu bildirilmiştir (74). Üçlü negatif meme kanserlerinin bir kısmından BRCA1/2 geninde varolan mutasyonlar sorumlu tutulmaktadır(75). $\mathrm{Bu}$ genin kodladığ 1 PARP enzimindeki mutasyon sonucunda tümör hücrelerinde platin ile oluşturulan DNA çift zincir hasarının homolog rekombinasyon yolu ile onarılamadığı ve hücrenin ölüme gittiği

Adress for correspondence: Ankara Onkoloji Hastanesi Tıbbi Onkoloji 06200 Ankara - Türkiye e-mail: ulkuarslan63@gmail.com

Available at www.actaoncologicaturcica.com

Copyright $\odot$ Ankara Onkoloji Hastanesi gösterilmiştir(76). TNT çalı̧̧masında $(\mathrm{N}=376)$, ER-, PgR- veya bilinmeyen, ve HER2- veya BRCA1/2+ metastatik veya nüks lokal ileri MK hastalarda karboplatin AUC6 $3 \mathrm{hft}$ bir uygulaması ile dosetaksel $100 \mathrm{mg} / \mathrm{m}^{2} 3 \mathrm{hft}$ bir uygulamas karşılaştırıldı(77). Progresyon halinde her iki kolda da çapraz geçiş izni vardı. Birincil sonlanım noktası ITT populasyonunda ORR, ikincil sonlanım noktaları ise PFS, OS, ORR (çapraz geçiş), ve toksisite idi. Planlı alt grup analizleri için BRCA1/2 mutasyonu, bazal-like subgruplar, HRD biyomarkırları belirlendi(77). Tüm grup için ortanca PFS karboplatin: 3.1 ay (95\% CI: 2.5-4.2) ve dosetaksel: 4.5 ay (95\% CI: 4.1-5.2), ortanca OS ise karboplatin (12.4 ay) ve dosetaksel (12.3 ay) ile benzerdi(77). ORR açısından eğer BRCA1/2 mut+ ise karboplatin ile cevap 2 kat arttı̆̆ gösterildi(78). Keza ortanca PFS bu grupta 6.8 aya karşın 4.8 ay ile BRCA1/2 mut+ ise daha iyi idi. BRCA1/2 mut- ise dosetaksel kolunda ortanca PFS daha iyi idi(3.1 vs 4.6)(78).

\section{Üçlü negatif MMK immünoterapi}

Bir Faz Ib çalışma olan KEYNOTE-012'de üçlü negatif PD-L1+ MMK'de 32 hastada Pembrolizumab $10 \quad \mathrm{mg} / \mathrm{kg} / 2$ haftada bir uygulandı(79). Kısmi yanıt veya stabil hastalıkta 24 ay tedavi verilmiş ve tam yanıt halinde ilaç kesilmesine izin verilmişti(79). İlk sunulduğunda ortanca yanıt süresine (DoR) ulaşılamamıştı (15-40+ hft), ayrıca cevaplı 5 hastanın 3'ünde DoR $\geq 11$ ay bulundu (79). KEYNOTE-012 çalışmasında pembrolizumabın toksisite profiline bakıldığında hafif artralji, halsizlik, miyalji ve yorgunluk başta geliyordu. Beş (\%15.6) hastada $\geq 3$ toksisite gözlenmişti ve bir hastanın ölümü tedaviye bağlanmıştı(80). ASCO 2017' de Adams ve ark tarafindan sunulan iki kollu faz II KEYNOTE-086 çalışmasının ön sonuçlarında üçlü negatif/ PD-L1 pozitif ve değerlendirme yapılabilen 52 hastada pembrolizumab monoterapisi ile ORR $\% 23,2 \mathrm{CR}$ ve 10 PR elde edilmişti(81). KEYNOTE 119 Faz III pembrolizumab çalışmasında daha önce 1 veya 2 sıra kemoterapi almış Üçlü negatif MMK'li hastalarda pembrolizumab ile doktor tercihi kemoterapi karşılaştırılması planlanmıştır. Bu çalışmanın hasta alımı tamamlanmış sonuçları beklenmektedir(82).

JAVELIN faz $1 \mathrm{~b}$ solid tümör çalışmasında daha önce birçok basamak tedavi almış progresif hastalığ olan 168 hastada human anti PD-L1 monoklonal antikor olan avelumab uygulandı(83). Üçlü negatif $(\mathrm{n}=58)$ olan hastaların 3'ünde kısmi cevap, 15'inde stabil hastalık elde edilmişti(ORR \%5.2). Buna karşın tüm grup $(\mathrm{N}=168)$ için 1 tam , 4 kısmi cevapl hasta varken (ORR\%3), 42 hastada stabil hastalık elde edilmişti. Üçlü negatif alt grupta eğer PD-L1 pozitif ise cevap oranı negatif olanlara göre yüksekti(\%22.2 vs \%2.6) Güvenlik profili kabul edilebilir bulundu(83). 
Atezolizumab ile yapılan faz 1a bir basket çalışmasında üçlü negatif, PD-L1 pozitif değerlendirilebilen 21 hastanın 4'ünde cevap ( 2 tam, 2 kısmi cevap)elde edilmişti(84). Bu çalışmaya alınan hasta sayısı 115 'e genişletildiğinde PD-L1 $\geq$ $\% 5$ ise ORR $\% 13$ iken $<\% 5$ ise $\% 5$ olarak bulundu.Ayrica ilk sira atezolizumab alanlarda cevap 2. ve 3. siraya göre ( $\% 26$ vs $\% 4$ vs $\% 8$ ) daha yüksekti(84). Impassion 130 faz III randomize çalışmada $(n=902)$ üçlü negatif MMK'de ilk sıra tedavide atezolizumab ile nab-paklitaksel vs nabpaklitaksel karşılaştırıldı (79). PD-L1 pozitif hastalarda ortanca PFS 7.5 vs 5.0 ay ile atezolizumab içeren kol lehine idi(HR:0.62,p<0.0001). OrtancaOrtanca OS 25.0 vs 15.5 ay ile kombine kol lehine bulundu(85).

Kemoterapi ve immünoterapi kombinasyon stratejileri:

Üçlü negatif MMK'de faz II bir çalışmada(n=32) atezolizumab $800 \mathrm{mg} 1$. ve 15. günler ile nabpaklitaksel $125 \mathrm{mg} / \mathrm{m} 21.8 .15$ günler $/ 28$ günde bir verilmesi değerlendirildi(86). Daha önce alınan tedavisi sayısı adjuvan/neoadjuvan dahil olmak üzere ortanca 5(1-10) idi. Tüm grup için ORR \%38 bulundu. İlk sira tedavi alan 13 hastada ORR \%46 idi. PD-L1 pozitif olanlarda cevap oranları hafif yüksek olsa da negatif olanlarda da cevap gözlenmişti(86). Faz III bir çalışmada daha önce tedavi almamış üçlü negatif MMK'inde atezolizumab ve nab-paklitaksel ile nab-paklitaksel ve plasebo karşılaştırıldı ve sonuçları beklenmektedir(87).Çeşitli basamaklarda tedavi olarak atezolizumab içeren kemoimmünoterapi kombinasyonları ile kemoterapinin karşılaştırıldı ğ faz III çalışmalar hasta alımına devam etmektedir.

ENHANCE 1 (KEYNOTE-150), eribulin mesilat $1.4 \mathrm{mg} / \mathrm{m} 2 / 1$. ve 8 . günler, pembrolizumab 200 $\mathrm{mg} / \mathrm{m} 2$ 1. gün 21 günde bir uygulanan başka bir fazIb/II kemoimmünoterapi çalışmasıdır(88). Faz II kısmı iki tabakalıdır. İlk grupta tedavi almamış MMK'li hastalar, ikincisinde 1-2 sira önceki tedaviye almış hastalar vardı. İlk sıra tedavi alan grupta ORR \%29.2 iken 2. grupta ORR\%22 idi.Cevaplı hastaların \%53'ünde cevap süresi 6 aydan uzundu (ortanca cevap süresi 8.3 ay)(88). KEYNOTE-355 çalışmasında üçlü negatif MMK'inde ilk sira tedavide kemoimmünoterapi ile kemoterapi karşılaştırılması planlanmış ve hasta alımı devam etmektedir(89).

\section{Üçlü negatif MMK( \pm BRCA $)$ PARP inhibitörleri \pm kemoterapi çalışmaları}

PARP enzimleri (PARP1 ve 2), DNA tek zincirinin kırıklarına cevap olarak baz eksizyon onarımında anahtar bir role sahiptir (90). Ayrica durmuş olan DNA replikasyon çatalının yeniden başlatılmasında ve BRCA1/BRCA2 ile ilişkili homolog rekombinasyonda rolleri olabileceği ileri sürülmüştür(91). PARP enzim inhibitörleri (PARPi)

Adress for correspondence: Ankara Onkoloji Hastanesi Tibbi Onkoloji 06200 Ankara - Türkiye e-mail: ulkuarslan63@gmail.com

Available at www.actaoncologicaturcica.com

Copyright $\odot$ Ankara Onkoloji Hastanesi
DNA onarım yolakları bozulmuş meme tümörlü hastalarda tek ajan olarak veya DNA hasarına neden olan sitotoksik ajan ile kombine kullanım açısından araştırılmaktadır (olaparib, rucaparib, niraparib, talazoparib ve veriparib). Aşağıda FDA onayı almış olan olaparib ve talazoparib'in faz III çalışmaları gözden geçirilmiştir.

Faz III OlympiAD çalışmasında Olaparib, BRCA1 veya BRCA2 mutasyonu olan HER2- MMK de doktor tercihi kemoterapi ile karşılaştıııldı(92). Birincil sonlanım olan PFS açısından olaparib standard tedaviye üstündü (7 vs 4.2 ay $\mathrm{HR}=0.58$, \%95 CI:0.43-0.80, p $<0.0001$ ) Ayrica ORR \%59.9 vs 28.8 ile olaparib lehine bulundu. Ancak genel sağkalım açısından her iki grup arasında fark yoktu( $(\mathrm{p}=0.57)$. Bu çalışmaya katılan hastaların hem deneysel hem standard tedavi kolunun yariya yakınını üçlü negatif hastalar oluşturuyordu ve bu hastalarda olaparib etkinliği daha güçlü idi. Olaparib, Ocak 2018 de bu çalışma ile daha önce neo-/adjuvan veya MMK için kemoterapi almış germline BRCA mutasyonu olan veya mutasyon şüphesi olan HER2-negatif lokal ileri ve/veya MMK tedavisinde FDA onayı aldı.Ancak olaparib alacak HR-pozitif olgularda daha endokrin tedavi almış olmak veya endokrin tedaviye uygun olmamak şartı konuldu(93). Güncellenmiş sonuçlarına bakıldığında ortanca genel sağkalımda 2.2 ay ile olaparib lehine bir fark olsa da istatistiki olarak anlamsızdı(19.3 vs 17.1,HR:0.90). İlk sıra olaparib kullanan hastalarda OS standard kola göre 7.9 ay daha iyiydi (94).

Başka bir faz III çalışmada (EMBRACA) BRCA1 veya BRCA2 mutasyonu olan MMK'de talazoparib ile doktor tercihi kemoterapi karşılaştırıldı(95). Deneysel kolda $\% 45$, kontrol kolunda $\% 41$ üçlü negatif hasta vardi. Her iki kolda da önceki tedavilerin 1/3'ü karboplatin veya sisplatin içeriyordu. Hem ortanca PFS (8.6 vs 5.6 ay $\mathrm{HR}=$ $0.542 \mathrm{p}<0.0001)$ hem de ORR \%62.6 vs 27.2 açısından talazoparib üstündü. Ancak bu çalışmada da OS'de bir iyileşme olsa da anlamlı fark sağlanamamıştı (22.3 vs 19.5 , HR:0.76,p=0.105). Talazoparib germline BRCA mutasyonu olan veya mutasyon şüphesi olan HER2-negatif lokal ileri ve/veya MMK tedavisinde 2018 yılında FDA onayı $\operatorname{ald}(96)$.

BRCA1 veya BRCA2 mutasyonu olan MMK'li hastalarda yapilan (Veliparib + karboplatin/paklitaksel(n=99) vs plasebo + karboplatin/paklitaksel( $\mathrm{n}=97)$ bir faz II çalışmada veliparib içeren kol lehine ORR (\%77.8 vs \%61.3) avantaj1 vard1(97). Ortanca PFS (14.1 vs 12.3 ay ) ve OS (28.3 vs 25.9 ay )açısından anlamlı olmasa da veliparib daha iyi görünmekteydi(97). Veliparib ile BROCADE 3 çalışması halen devam etmektedir (98). Ayrica BRCA1/2 mutant, HER2- MMK hastalarda faz III niraparib vs doktor tercihi 
kemoterapi ajanı ile yapılan BRAVO çalışması devam etmektedir(99).

\section{$\ddot{U} c ̧$ lï negatif MMK bir kısmında androjen reseptörü (AR) hedefleyen tedaviler:}

Üçlü negatif MMK bir kısmında androjen reseptörü (AR) varlığının gösterilmesi AR inhibitörlerinin bu hasta grubunda çalışılmasına neden oldu. Aşağıda enzalutamid, abirateron ve bikalutamid ile yapılan faz II çalışmalar özetlenmiştir:

Enzalutamid, Androjenin AR'ye bağlanmasını ve AR'nin nükleusa gidişini /DNA bağlanmasını inhibe eder(100). Metastatik üçlü negatif/AR pozitif meme kanserinde yapılan bir faz II çalışmada Enzalutamid ile ile 16. haftada CBR 35\% (26/75), 24. haftada CBR: $29 \%$ (22/75),CR veya PR: $3 \%$ (6/75),ortanca PFS: 14.7 hafta bulundu(101). Ortanca sağkalım İTT populasyonunda 12.7 ay, değerlendirilebilen alt grupta 17.6 ay idi (102) . Abiraterone asetat CYP17'nın irreversibl inhibitörüdür(103). Metastatik üçlü negatif/AR pozitif meme kanserinde yapılan bir faz II çalışmada Abiraterone asetat + prednizon ile 6. ayda CBR 20\% (1/34 hasta CR; 5 hasta SD $\geq 6$ ay, 1 hasta PR 12 .ay da) ortanca PFS 2.8 ay olarak bulundu(104). Bicalutamide bir androjen antagonistidir(105).Yukardakilerle benzer bir populasyondaki çalışmasında 6. ayda CBR 19\% (5/26, SD > 6 ay; CR yok veya PR) ve ortanca PFS ise 12 hafta bulundu(106). Henüz üçlü negatif MMK tedavi rehberlerine girmiş $\mathrm{AR}$ hedefleyen tedavi mevcut değildir.

Sonuç olarak, HR+ HER2- MMK de yeni hormonal tedavi kombinasyonları ile PFS uzama gözlendi ancak bunun genel sağkalıma etkisini gösteren sonuçları beklemek gereklidir. Hormon reseptör pozitif MMK'de kemoterapi çoklu hormonoterapi basamaklarından sonra hastalı ilerlemesi veya viseral kriz durumu hariç verilmemelidir. HER2pozitif MMK de yeni ve sağkalıma katkısı olan ajanlar kullanıma girdi. Üçlü negatif MMK için yeni ufuklar açacak tedavi çalışmaları devam etmektedir.

\section{REFERANSLAR}

1. www.who.int/cancer/prevention/diagnosis.../breastcancer

2. https://hsgm.saglik.gov.tr/tr/kanser-istatistikleri

3. O'Shaughnessy J. Extending survival with chemotherapy in metastatic breast cancer. Oncologist. 2005;10 Suppl 3:20-9.

4. Mariotto A. B., Etzioni R., Hurlbert M., Penberthy L., and Mayer M. Estimation of the Number of Women Living with Metastatic Breast Cancer in the United States.Cancer Epidemiol Biomarkers Prev; 26(6); 809-15. _2017 AACR.

5. Cohen $\mathrm{MH}$, Hirschfeld $\mathrm{S}$, Flamm Honig $\mathrm{S}$, et al. Drug Approval Summaries: Arsenic Trioxide, Tamoxifen Citrate, Anastrazole, Paclitaxel, Bexarotene.The Oncologist 2001;6:4-11

6. Cohen MH, Johnson JR, Li N, Chen G, Pazdur R.Approval summary: letrozole in the treatment of postmenopausal women with advanced breast cancer.Clin Cancer Res. 2002 Mar;8(3):665-9.

7. https://www.accessdata.fda.gov

8. Lønning $\mathrm{P}$, Pfister $\mathrm{C}$, Martoni A, Zamagni C. Pharmacokinetics of third-generation aromatase inhibitors. Semin Oncol. 2003 Aug;30(4 Suppl 14):23-32.

9. Bross PF, Cohen MH, Williams GA, Pazdur R.FDA drug approval summaries: fulvestrant. Oncologist. 2002;7(6):477-80

10. Carlson RW. The history and mechanism of action of fulvestrant. Clin Breast Cancer. 2005 Apr;6 Suppl $1:$ S5-8.

11. Bonneterre J, Buzdar A, Nabholtz JM, et al. Arimidex Writing Committee; Investigators Committee Members. Anastrozole is superior to tamoxifen as first-line therapy in hormone receptor positive advanced breast carcinoma.Cancer. 2001 Nov 1;92(9):2247-58.

12. Mouridsen $H$, Gershanovich $M$, Sun $Y$, et al. Phase III study of letrozole versus tamoxifen as first-line therapy of advanced breast cancer in postmenopausal women: analysis of survival and update of efficacy from the International Letrozole Breast Cancer Group. J Clin Oncol. 2003 Jun 1;21(11):2101-9.

13. Paridaens R. J., Dirix L.Y., Beex L. V., et al. Phase III Study Comparing Exemestane With Tamoxifen As First-Line Hormonal Treatment of Metastatic Breast Cancer in Postmenopausal Women: The European Organisation for Research and Treatment of Cancer Breast Cancer Cooperative Group. J Clin Oncol 26:4883-4890.

14. Mauri D, Pavlidis N, Polyzos NP, Ioannidis JP. Survival with aromatase inhibitors and inactivators versus standard hormonal therapy in advanced breast cancer: meta-analysis. J Natl Cancer Inst. 2006 Sep 20;98(18):1285-91.

15. Robertson JF, Llombart-Cussac A, Rolski J, et al. Activity of fulvestrant $500 \mathrm{mg}$ versus anastrozole 1 mg as first-line treatment for advanced breast cancer: results from the FIRST study. J Clin Oncol. 2009 Sep 20;27(27):4530-5. doi: 10.1200/JCO.2008.21.1136. Epub 2009 Aug 24.

16. Ellis MJ, Llombart-Cussac A, Feltl D, et al. Fulvestrant $500 \mathrm{mg}$ Versus Anastrozole $1 \mathrm{mg}$ for the First-Line Treatment of Advanced Breast Cancer: Overall Survival Analysis From the Phase II FIRST Study.J Clin Oncol. 2015 Nov 10;33(32):3781-7.

17. Robertson JFR, Bondarenko IM, Trishkina E, et al. Fulvestrant $500 \mathrm{mg}$ versus anastrozole $1 \mathrm{mg}$ for hormone receptor-positive advanced breast cancer (FALCON): an international, randomised, doubleblind, phase 3 trial.Lancet. 2016;388(10063):29973005.

18. Johnston SR. New strategies in estrogen receptorpositive breast cancer.Clin Cancer Res. 2010 ;16(7):1979-87.

19. Musgrove E A. and Sutherland RL. Biological determinants of endocrine resistance in breast cancer. Nature Reviews Cancer,2009;9:631-643.

20. Abraham J , Coleman R, Elias A et al. Use of cyclin-dependent kinase (CDK) 4/6 inhibitors for hormone receptor-positive, human epidermal growth factor receptor 2-negative, metastatic breast cancer: a 
roundtable discussion by The Breast Cancer Therapy Expert Group (BCTEG).

21. Boulay A, Rudloff J, Ye J, et al. Dual inhibition of mTOR and estrogen receptor signaling in vitro induces cell death in models of breast cancer. Clin Cancer Res. 2005;11(14):5319-5328.

22. Baselga J, Campone M, Piccart M, et al. Everolimus in postmenopausal hormone-receptor-positive advanced breast cancer. N Engl J Med. 2012 ;366(6):520-9.

23. Baselga $\mathrm{J}$, Im S-A, Iwata $\mathrm{H}$, et al. PIK3CA status in circulating tumor DNA (ctDNA) predicts efficacy of buparlisib (BUP) plus fulvestrant (FULV) in postmenopausal women with endocrine-resistant HR+/HER2 - advanced breast cancer (BC): First results from the randomized, phase III BELLE-2 trial. SABCS 2015. Abstract S6-01.

24. Baselga J, Dent SF, Cortés J, Im Y-H, Diéras V, Harbeck N . Phase III study of taselisib (GDC-0032) + fulvestrant (FULV) v FULV in patients (pts) with estrogen receptor (ER)-positive, PIK3CA-mutant (MUT), locally advanced or metastatic breast cancer (MBC): Primary analysis from SANDPIPER. J Clin Oncol 36, no. 18_suppl. LBA1006

25. André F, Ciruelos EM, Rubovszky G et al. Alpelisib (ALP) + fulvestrant (FUL) for advanced breast cancer (ABC): results of the Phase 3 SOLAR-1 trial. ESMO 2018 LBA3_PR.

26. Yardley DA, Ismail-Khan RR, Melichar $B$,et al. Randomized phase II, double-blind, placebocontrolled study of exemestane with or without entinostat in postmenopausal women with locally recurrent or metastatic estrogen receptor-positive breast cancer progressing on treatment with a nonsteroidal aromatase inhibitor. J Clin Oncol. 2013;31(17):2128-35.

27. Yeruva L, Zhao F, Miller K. et al. E2112: randomized phase iii trial of endocrine therapy plus entinostat/placebo in patients with hormone receptorpositive advanced breast cancer. npj Breast Cancer, 4; 1 .2018.

28. Finn RS, Crown JP, Lang I et al. The cyclindependent kinase 4/6 inhibitor palbosiklib in combination with letrozole versus letrozole alone as first-line treatment of oestrogen receptor-positive, HER2-negative, advanced breast cancer (PALOMA1/TRIO-18): a randomised phase 2 study. Lancet Oncol. 2015;16(1):25-35

29. Finn RS, Martin M, Rugo HS, et al. Palbosiklib and Letrozole in Advanced Breast Cancer. N Engl J Med. 2016 Nov 17;375(20):1925-1936.

30. Turner NC, Ro J, André F, Loi S, et al. Palbosiklib in Hormone-Receptor-Positive Advanced Breast Cancer. N Engl J Med. 2015 ;373(3):209-19.

31. Cristofanilli M, Turner NC, Bondarenko I, et al. Fulvestrant plus palbociclib versus fulvestrant plus placebo for treatment of hormone-receptor-positive, HER2-negative metastatic breast cancer that progressed on previous endocrine therapy (PALOMA-3): final analysis of the multicentre, double-blind, phase 3 randomised controlled trial. Lancet Oncol. 2016 ;17(4):425-439.

32. Cristofanilli, Slamon DJ., Ro J et al. Overall survival (OS) with palbociclib plus fulvestrant in women with hormone receptor-positive $(\mathrm{HR}+)$, human epidermal growth factor receptor 2-negative (HER2-) advanced breast cancer (ABC): Analyses from PALOMA-3. Ann Oncol 2018;29(8): LBA2_PR. mdy424.009.

33. Sledge GW Jr, Toi M, Neven P, et al. MONARCH 2: Abemaciclib in Combination With Fulvestrant in Women With HR+/HER2- Advanced Breast Cancer Who Had Progressed While Receiving Endocrine Therapy. J Clin Oncol. 2017;35(25):2875-2884.

34. Goetz MP, Toi M, Campone M, et al. MONARCH 3 : Abemaciclib As Initial Therapy for Advanced Breast Cancer. J Clin Oncol. 2017 Nov 10;35(32):36383646.

35. Hortobagyi GN, Stemmer SM, Burris HA, et al. Ribociclib as First-Line Therapy for HR-Positive, Advanced Breast Cancer. N Engl J Med. 2016;375(18):1738-1748.

36. Hortobagyi GN, Stemmer SM, Burris HA, et al. Updated results from MONALEESA-2, a phase III trial of first-line ribociclib plus letrozole versus placebo plus letrozole in hormone receptor-positive, HER2-negative advanced breast cancer. Ann Oncol. 2018;29(7):1541-1547.

37. Slamon DJ, Neven P, Chia S, et al. Phase III Randomized Study of Ribociclib and Fulvestrant in Hormone Receptor-Positive, Human Epidermal Growth Factor Receptor 2-Negative Advanced Breast Cancer:MONALEESA-3. J Clin Oncol 2018;36:2465-2472.

38. Tripathy D, Im S-A, Colleoni M, et al. Ribociclib plus endocrine therapy for premenopausal women with hormone-receptor-positive, advanced breast cancer (MONALEESA-7): a randomised phase 3 trial. Lancet Oncol 2018; 19: 904-15

39. Wilcken N, Hornbuckle J, Ghersi D.Chemotherapy alone versus endocrine therapy alone for metastatic breast cancer. Cochrane Database Syst Rev. 2003;(2):CD002747.

40. www.ncen.org/breast cancer:version $4 / 2018$.

41. Slamon DJ, Clark GM, Wong SG, Levin WJ, Ullrich A, McGuire WL. Human breast cancer: correlation of relapse and survival with amplification of the HER2/neu oncogene. Science. 1987; 235(4785):177-82.

42. Pegram M, Slamon D. Biological rationale for HER2/neu (c-erbB2) as a target for monoclonal antibody therapy. Semin Oncol. 2000; 27(5 Suppl 9):13-9.

43. Citri A, Yarden Y. EGF-ERBB signalling: towards the systems level. Nat Rev Mol Cell Biol. 2006; 7(7):505-16.

44. Harari D, Yarden Y. Molecular mechanisms underlying ErbB2/HER2 action in breast cancer. Oncogene. 2000; 19(53):6102-14.

45. Baselga J, Swain SM. Novel anticancer targets: revisiting ERBB2 and discovering ERBB3. Nat Rev Cancer. 2009; 9(7):463-75.

46. Carter P, Presta L, Gorman CM, Ridgway JB, Henner $\mathrm{D}$, Wong WL, et al. Humanization of an antip185HER2 antibody for human cancer therapy. Proc Natl Acad Sci U S A. 1992; 89(10):4285-9.

47. Agus DB, Akita RW, Fox WD, Lewis GD, Higgins B, Pisacane PI, et al. Targeting ligand-activated ErbB2 signaling inhibits breast and prostate tumor growth. Cancer Cell. 2002; 2(2):127-37. 
48. Lewis Phillips GD, Li G, Dugger DL, Crocker LM, Parsons KL, Mai E, et al. Targeting HER2-positive breast cancer with trastuzumab-DM1, an antibodycytotoxic drug conjugate. Cancer Res. 2008; 68(22):9280-90.

49. Konecny GE, Pegram MD, Venkatesan N, Finn R, Yang G, Rahmeh M, et al. Activity of the dual kinase inhibitor lapatinib (GW572016) against HER-2overexpressing and trastuzumab-treated breast cancer cells. Cancer Res. 2006; 66(3):1630-9.

50. Slamon DJ, Leyland-Jones $B$, Shak $S$,et al. Use of chemotherapy plus a monoclonal antibody against HER2 for metastatic breast cancer that overexpresses HER2. N Engl J Med. 2001;344(11):783-92.

51. Seidman A, Hudis C, Pierri MK et al. Cardiac dysfunction in the trastuzumab clinical trials experience. J Clin Oncol 2002; 20(5):1215-1221.

52. Marty $M$, Cognetti $F$, Maraninchi D, et al.Randomized phase II trial of the efficacy and safety of trastuzumab combined with docetaxel in patients with human epidermal growth factor receptor 2positive metastatic breast cancer administered as first-line treatment: the M77001 study group. J Clin Oncol. 2005 ;23(19):4265-74.

53. Geyer CE, Forster J, Lindquist D, et al. Lapatinib plus capecitabine for HER2-positive advanced breast cancer. N Engl J Med 2006; 355:2733-2743

54. Baselga J, Cortes H, Kim S-B et al Pertuzumab plus Trastuzumab plus Docetaxel for Metastatic Breast Cancer. N Engl J Med 2012; 366:109-119

55. Swain S, Baselga J, Kim S-B et al. Pertuzumab, Trastuzumab, and Docetaxel in HER2-Positive Metastatic Breast Cancer. N Engl J Med 2015; 372:724-734

56. Verma S, Miles D, Gianni L, et al. Trastuzumab emtansine for HER2-positive advanced breast cancer. N Engl J Med. 2012;367(19):1783-91.

57. Krop IE, Kim SB, Martín AG, et al.Trastuzumab emtansine versus treatment of physician's choice for pretreated HER2-positive advanced breast cancer (TH3RESA): a randomised, open-label, phase 3 trial. Lancet Oncol. 2014;7:689-99.

58. Krop IE, Kim SB, Martín AG, et al.Trastuzumab emtansine versus treatment of physician's choice for pretreated HER2-positive metastatic breast cancer (TH3RESA): final overall survival results from a randomised open-label phase 3 trial. Lancet Oncol. 2017;6:743-754.

59. Blackwell KL, Burstein HJ, Storniolo AM, et al. Randomized study of Lapatinib alone or in combination with trastuzumab in women with ErbB2positive, trastuzumab-refractory metastatic breast cancer. J Clin Oncol. 2010 ;28(7):1124-30

60. Blackwell KL, Burstein HJ, Storniolo AM, et al. Overall survival benefit with lapatinib in combination with trastuzumab for patients with human epidermal growth factor receptor 2-positive metastatic breast cancer: final results from the EGF104900 Study. J Clin Oncol. $2012 ; 30(21): 2585-92$.

61. Dang C, Iyengar N, Datko F et al. Phase II study of paclitaxel given once per week along with trastuzumab and pertuzumab in patients with human epidermal growth factor receptor 2-positive metastatic breast cancer.J Clin Oncol. 2015 ;33:4427.

Adress for correspondence: Ankara Onkoloji Hastanesi Tıbbi Onkoloji 06200 Ankara - Türkiye e-mail: ulkuarslan63@gmail.com

Available at www.actaoncologicaturcica.com

Copyright $\odot$ Ankara Onkoloji Hastanesi
62. Dang C, Iyengar N, Datko F et al. Phase II study of paclitaxel given once per week along with trastuzumab and pertuzumab in patients with human epidermal growth factor receptor 2-positive metastatic breast cancer.J Clin Oncol. 2015 ;33:4427.

63. Perez EA, López-Vega JM, Petit T, et al. Safety and efficacy of vinorelbine in combination with pertuzumab and trastuzumab for first-line treatment of patients with HER2-positive locally advanced or metastatic breast cancer: VELVETCohort 1 final results.Breast Cancer Res. 2016 ;18:126.

64. Perez E A, Barrios C H., Eiermann W et al. Phase III, randomized study of first-line trastuzumab emtansine (T-DM1) \pm pertuzumab (P) vs. trastuzumab + taxane (HT) treatment of HER2positive MBC: Final overall survival (OS) and safety from MARIANNE. J Clin Oncol 2017: 15; abstract no 1003.

65. Bauer KR, Brown M, Cress RD, Parise CA, Caggiano V. Descriptive analysis of estrogen receptor (ER)negative, progesterone receptor (PR)-negative, and HER2-negative invasive breast cancer, the so-called triple-negative phenotype: a population-based study from the California cancer Registry. Cancer. 2007;9:1721-8.

66. Sørlie T, Perou CM, Tibshirani R,et al. Gene expression patterns of breast carcinomas distinguish tumor subclasses with clinical implications. Proc Natl Acad Sci USA. 2001; 98:10869-74.

67. Le Du F, Eckhardt BL, Lim B, et al. Is the future of personalized therapy in triple-negative breast cancer based on molecular subtype?Oncotarget. 2015;6:12890-12908,

68. Burstein MD, Tsimelzon A, Poage GM,et al. Comprehensive Genomic Analysis Identifies Novel Subtypes and Targets of Triple-negative Breast Cancer. Clin Cancer Res. 2015 ;21(7):1688-98.

69. Lehmann BD, Bauer JA, Chen X, et al. Identification of human triple-negative breast cancer subtypes and preclinical models for selection of targeted therapies. J Clin Invest. 2011; 121:2750-67.

70. Kassam F, Enright K, Dent R, et al. Survival outcomes for patients with metastatic triple-negative breast cancer: implications for clinical practice and trial design. Clin Breast Cancer. 2009;9(1):29-33.

71. Albain KS, Nag SM, Calderillo-Ruiz G, et al. Gemcitabine plus Paclitaxel versus Paclitaxel monotherapy in patients with metastatic breast cancer and prior anthracycline treatment. J Clin Oncol. 2008;26(24):3950-7.

72. O'Shaughnessy J, Miles D, Vukelja S. et al. Superior survival with capecitabine plus docetaxel combination therapy in anthracycline-pretreated patients with advanced breast cancer: phase III trial results.J Clin Oncol. 2002;20:2812-2823.

73. Miles D, Vukelja S, Moiseyenko V, et al. Survival benefit with capecitabine/docetaxel versus docetaxel alone: analysis of therapy in a randomized phase III trial.Clin Breast Cancer. 2004;5:273-278.

74. Sledge GW, Neuberg D, Bernardo P, et al. Phase III trial of doxorubicin, paclitaxel, and the combination of doxorubicin and paclitaxel as front-line chemotherapy for metastatic breast cancer: an 
intergroup trial (E1193).J Clin Oncol. 2003;21:588592.

75. Hahnen E, Hauke J, Engel C, Neidhardt G, Rhiem K, Schmutzler R K. Germline Mutations in TripleNegative Breast Cancer Breast Care 2017;12:15-19.

76. Papadimitriou $M$, Theodosopoulos $T$, Baltas $D$, Papadimitriou CA. Therapeutic targets for metastatic triple-negative breast cancer: focus on PARP inhibition. Global J Breast Cancer Res 2017;5:12-21.

77. Tutt A, Ellis P, Kilburn L, et al. The TNT trial: A randomized phase III trial of carboplatin (C) compared with docetaxel (D) for patients with metastatic or recurrent locally advanced triple negative or BRCA1/2 breast cancer (CRUK/07/012). SABCS 2014. Abstract S3-01.

78. Tutt A, Tovey H, Cheang MCU, et al. Carboplatin in BRCA1/2-mutated and triple-negative breast cancer BRCAness subgroups: the TNT Trial. Nat Med. 2018;24(5):628-637.

79. Nvea R, Chow LQ, Dees EC, et al. Pembrolizumab in Patients With Advanced Triple-Negative Breast Cancer: Phase Ib KEYNOTE-012 Study. SABCS 2014. Abstract S1-09.

80. Nanda R, Chow LQ, Dees EC, et al. Pembrolizumab in Patients With Advanced Triple-Negative Breast Cancer: Phase Ib KEYNOTE-012 Study. J Clin Oncol. 2016;34(21):2460.

81. Adams S, Schmid P, Rugo HS.et al. Phase 2 study of pembrolizumab (pembro) monotherapy for previously treated metastatic triple-negative breast cancer (mTNBC): KEYNOTE-086 cohort A. J Clin Oncol. 2017;35 (suppl; abstr 1008).

82. ClinicalTrials.gov Identifier: NCT02555657

83. Dirix LY, Takacs I, Jerusalem G, et al. Avelumab, an anti-PD-L1 antibody, in patients with locally advanced or metastatic breast cancer: a phase $1 b$ JAVELIN Solid Tumor study. Breast Cancer Res Treat. 2018;167(3):671-686.

84. Schmid P, Cruz C, Braiteh F S. Et al. Atezolizumab in metastatic TNBC (mTNBC): Long-term clinical outcomes and biomarker analyses. Cancer Res. 2017;77 (suppl; abstr 2986).

85. Schmid P, Adams S, Rugo HS,et al. - IMpassion130: Results from a global, randomised, double-blind, phase 3 study of atezolizumab (atezo) + nabpaclitaxel (nab-P) vs placebo + nab-P in treatmentnaive, locally advanced or metastatic triple-negative breast cancer (mTNBC) ESMO 2018. LBA1_PR.

86. Adams S, Robinson Diamond J, Hamilton EP et al. Phase Ib trial of atezolizumab in combination with nab-paclitaxel in patients with metastatic triplenegative breast cancer (mTNBC). J Clin Oncol. 2017;35 (suppl; abstr 1088).

87. ClinicalTrials.gov Identifier: NCT02425891

88. Tolaney S, Savulsky C, Aktan G et al. Phase $1 b / 2$ study to evaluate eribulin mesylate in combination with pembrolizumab in patients with metastatic triple-negative breast cancer.San Antonio Breast Cancer Symposium. 2017; abstr P5-15-02.

89. ClinicalTrials.gov Identifier: NCT02819518

90. Curtin NJ. PARP inhibitors for cancer therapy. Expert Rev Mol Med.2005;7:1-20.

91. Bryant HE, Petermann E, Schultz N, et al. PARP is activated at stalled forks to mediate Mre11-dependent replication restart and recombination. EMBO J. 2009;28:2601-2615.

92. Robson M, Im SA, Senkus E, et al. et al. Olaparib for Metastatic Breast Cancer in Patients with a Germline BRCA Mutation.N Engl J Med. 2017;377(6):523533.

93. https://www.accessdata.fda.gov/drugsatfda.../208558 s001lbl.

94. Robson M E, Im S-A, Senkus E, et al. OlympiAD final overall survival: Olaparib versus chemotherapy treatment of physician's choice (TPC) in patients with HER2-negative metastatic breast cancer ( $\mathrm{mBC}$ ) and a germline BRCA mutation (gBRCAm).AACR; Cancer Res 2018;78(13 Suppl):Abstract nr CT038.

95. Litton J, Rugo HS, Ettl J, et al. EMBRACA: A phase 3 trial comparing talazoparib, an oral PARP inhibitor, to physician's choice of therapy in patients with advanced breast cancer and a germline BRCA mutation [abstract]. In: Proceedings of the 2017 San Antonio Breast Cancer Symposium; 2017 Dec 5-9; San Antonio, TX. Philadelphia (PA): AACR; Cancer Res 2018;78(4 Suppl):Abstract nr GS6-07.

96. https://www.fda.gov/Drugs/.../ucm623540.htm

97. Han H S, Diéras V ,Robson M et al. Veliparib with temozolomide or carboplatin/paclitaxel versus placebo with carboplatin/paclitaxel in patients with BRCA1/2 locally recurrent/metastatic breast cancer: randomized phase II study.Annal Oncol.2018;29(1), 154-161

98. ClinicalTrials.gov Identifier: NCT02163694

99. ClinicalTrials.gov Identifier: NCT01905592

100. XTANDI (enzalutamide) . Summary of Product Characteristics, 2013. Available at: http://www.ema.europa.eu/docs/en_GB/document_li brary/EPAR Product Information/human/002639/ WC500144996.pdf.

101. Traina T A, Miller K, Yardley D A.,et al. Results from a phase 2 study of enzalutamide (ENZA), an androgen receptor (AR) inhibitor, in advanced AR+ triple-negative breast cancer (TNBC). J Clin Oncol 2015,33( 15) suppl 1003-1003.

102. Traina $T$ A, Miller $K$, Yardley $D$ A.,et al. Enzalutamide for the Treatment of Androgen Receptor-Expressing Triple-Negative Breast Cancer. J Clin Oncol 2018, 36:884-890.

103. Rowlands MG, Barrie SE, Chan F, et al. Esters of 3pyridylacetic acid that combine potent inhibition of 17 alpha-hydroxylase/C17,20-lyase (cytochrome P45017 alpha) with resistance to esterase hydrolysis. J Med Chem. 1995;38(21):4191-7.

104. Bonnefoi H, Grellety T, Tredan O, et al. A phase II trial of abiraterone acetate plus prednisone in patients with triple-negative androgen receptor positive locally advanced or metastatic breast cancer (UCBG 12-1). Ann Oncol. 2016 May;27(5):812-8.

105. Osguthorpe DJ, Hagler AT.Mechanism of androgen receptor antagonism by bicalutamide in the treatment of prostate cancer. Biochemistry. 2011;50(19):410513

106. Gucalp A, Tolaney S, Isakoff SJ, et al. Phase II trial of bicalutamide in patients with androgen receptorpositive, estrogen receptor-negative metastatic Breast Cancer. Clin Cancer Res. 2013 ;19(19):5505-12. 